\title{
Research
}

\section{Multi-omics Comparison Reveals Landscape of Citrus limon and Citrus sinensis Response to 'Candidatus Liberibacter asiaticus'}

\author{
Elizabeth L. Chin ${ }^{1}$ | John Ramsey,3 ${ }^{2,3}$ Surya Saha $^{3}$ (1) | Darya Mishchuk ${ }^{1} \mid$ Juan Chavez ${ }^{4}$ | Kevin Howe ${ }^{2,3}$ | \\ Xuefei Zhong $^{4}$ | Mirella Flores-Gonzalez ${ }^{3}$ | Elizabeth Mitrovic ${ }^{5}$ | MaryLou Polek ${ }^{6}$ | Kris Godfrey ${ }^{5}$ | \\ Lukas A. Mueller ${ }^{2} \mid$ James Bruce ${ }^{4} \mid$ Michelle Heck $^{2,3,7^{(0)}} \mid$ Carolyn M. Slupsky ${ }^{1,+}$ (i) |
}

${ }^{1}$ Department of Food Science and Technology, University of California, Davis, CA

2 Emerging Pests and Pathogens Research Unit, Robert W. Holley Center for Agriculture and Health, USDA Agricultural Research Service, Ithaca, NY

${ }^{3}$ Boyce Thompson Institute for Plant Research, Ithaca, NY

${ }^{4}$ Department of Genome Sciences, University of Washington, Seattle, WA

${ }^{5}$ Contained Research Facility, University of California, Davis, CA

${ }^{6}$ National Clonal Germplasm Repository for Citrus \& Dates, Riverside, CA

7 Plant Pathology and Plant Microbe Biology Section, School of Integrative Plant Science, Cornell University, Ithaca, NY

† Corresponding author: C. Slupsky; cslupsky@ ucdavis.edu

Accepted for publication 7 November 2020 .

\begin{abstract}
Funding
This research was funded through the California Citrus Research Board grants 5300-150 and 5300155. This project was made possible in part by support from the USDA National Institute of Food and Agriculture Hatch Project 1021411. The 600 $\mathrm{MHz}$ NMR is supported through $\mathrm{NIH}$ grant 1S10RR011973-01. The Agilent 8900 ICP-MS was purchased with funding from the UC Davis Research Core Facilities Program's (RCFP's) CRCF Enhancement Funding Program. The Illumina HiSeq4000 instrument at the UC Davis Genome Center was supported by the NIH Shared Instrumentation Grant 1S10OD010786-01. The Citrusgreening.org portal and associated resources were funded through USDA-NIFA grant 201570016-23028.
\end{abstract}

The author(s) declare no conflict of interest.

$\boldsymbol{e}$-Xtra: One file containing supplementary material and four supplementary datasets are available online.

\begin{abstract}
Comparison of the metabolic changes prior to symptom development upon infection with Candidatus Liberibacter asiaticus (CLas), the bacterium associated with citrus greening disease, between citrus hosts with different tolerances is lacking. The objective of this study was to compare the early response of Lisbon lemon (Citrus limon) and Washington navel orange (Citrus sinensis [L.] Osbeck), two citrus species commercially important to California, to CLas through graft inoculation. Here, we compare the transcriptome, proteome, and metabolome response, using RNA sequencing, liquid chromatography tandem mass spectrometry, and ${ }^{1} \mathrm{H}$ nuclear magnetic resonance, respectively, from our two recently published studies examining the response of the lemon and navel oranges separately, and introduce new micronutrient data from inductively coupled plasma mass spectrometry analysis, focusing on lemons at 10 and 14 weeks postgrafting (wpg), and navels at 8 and 18 wpg, prior to symptom development. Several micronutrients accumulated in presymptomatic infected lemons compared with controls, whereas little change was observed in the navels. Photosynthesis proteins were substantially altered by CLas infection in navels, with fewer changes observed in lemons. The metabolome differed between control and infected navels throughout infection, although differences between control and infected lemons were identified only after symptom expression. Taken together, these findings highlight differences in response to CLas between two varieties with differing tolerances.
\end{abstract}

Keywords: 'Candidatus Liberibacter asiaticus', huanglongbing, citrus greening disease, transcriptomics, proteomics, metabolomics, citrus

'Candidatus Liberibacter asiaticus' (CLas) is one of at least three species of phloemrestricted, fastidious, gram negative bacteria in the Rhizobiaceae associated with the citrus disease huanglongbing (HLB). Due to the inability to culture CLas and its relatives, experiments to understand the virulence genes and pathology are limited to 
studying the bacterium in the context of host infection or in its insect vector, the hemipteran Diaphorina citri. HLB was first discovered in Florida in 2005 and in California in 2012. Since then, production of oranges in the United States for processing declined by $72.2 \%$ from the $2007-2008$ to the $2017-2018$ growing seasons, and for fresh production by $20.5 \%$ (Dala-Paula et al. 2019), primarily in Florida. Of concern is the number of $C$ Las-infected trees that are rapidly increasing in California (CDFA 2012; Citrus Pest \& Disease Prevention Program 2020), which are predominantly for fresh consumption. In natural infections, $C$ Las is spread by $D$. citri and can also be spread by grafting infected material onto healthy trees (Grafton-Cardwell et al. 2005, 2013). D. citri are widespread in Florida and are spreading in California. HLB causes leaf chlorosis ("yellow mottle"), poor fruit appearance and taste, low fruit yield, and premature tree death (Bové 2006; Gottwald et al. 2007). HLB symptoms can take years to manifest after initial infection with CLas (Gottwald 2010), and presymptomatic trees are especially problematic when $D$. citri are present because they serve as clandestine sources of inoculum. Newly infected plants become infectious to psyllids approximately 2 weeks after inoculation (Lee et al. 2015).

There is currently no known cure for HLB, and no known citrus varieties are resistant to CLas, although different citrus varieties and hybrids have varying levels of tolerance (Cevallos-Cevallos et al. 2012; Folimonova et al. 2009; McCollum et al. 2016; Wang et al. 2017b). Some varieties of citrus respond to CLas by increasing production of $\mathrm{H}_{2} \mathrm{O}_{2}$ and ATP while lowering gene expression levels of key enzymes participating in reactive oxygen species detoxification (Pitino et al. 2017). During the presymptomatic stage, starch accumulation, phloem collapse, and changes in cell wall-related genes appear to be variety specific (Fan et al. 2012, 2013). Transcriptome differences between infected tolerant and susceptible grapefruit field trees revealed higher gene expression for abiotic and biotic stress in the tolerant Jackson variety, whereas the susceptible Marsh variety exhibited higher gene expression of proteins involved in RNA, DNA, and protein biosynthesis, as well as cell wall organization (Wang et al. 2016). In a separate study, microarray analyses of susceptible Cleopatra mandarins compared with a tolerant US-897 hybrid revealed that during infection more genes were upregulated in the susceptible variety relative to healthy controls than in the tolerant variety (Albrecht and Bowman 2012). Other studies examining healthy susceptible and tolerant varieties suggest that there may be differences in basal metabolite composition that may contribute to susceptibility or tolerance to CLas (Hijaz et al. 2020; Killiny et al. 2018). HLB symptoms have been shown to be more severe in sweet orange $(C$. sinensis), Cleopatra mandarin ( $C$. reticulate Blanco), citron (C. medica), and C. macrophylla, whereas Sun Chu Sha mandarin (C. reticulata Blanco), Persian lime (C. aurantifolia [Christm.] Swingle), and several lemon varieties exhibit less severe HLB symptoms (Fan et al. 2012; Folimonova et al. 2009; Killiny 2017; McCollum et al. 2016). These studies highlight the fact that not all citrus respond identically, and it is important to understand and compare how susceptible and tolerant varieties respond to the pathogen.

We previously published on the impact of CLas on transcriptome, proteome, and metabolome of Washington navel orange (C. sinensis [L.] Osbeck) (Chin et al. 2019) and Lisbon lemon (C. limon L. Burm.f.) (Ramsey et al. 2020) during the early stages of infection. Here, we compare and contrast the impact of $C$ Las on a susceptible (navel) and a more tolerant (lemon) variety of citrus, and we additionally report on the impact of $C$ Las on the micronutrient profiles (inductively coupled plasma mass spectrometry [ICP-MS]) of leaf tissue from each variety of citrus. We believe that specifically comparing the response of these two varieties is valuable because, to our knowledge, this has not been done prior to symptom development, and these two citrus varieties represent commercially important varieties in California.

\section{MATERIALS AND METHODS}

Full details of materials and methods are provided in Supplementary File S1 (SI Methods).

\section{Plant material}

All plants were grown and maintained in an insect-free greenhouse at the Contained Research Facility at the University of California, Davis. Lisbon lemon (C. limon) and Washington navel orange ( $C$. sinensis) scions on Carrizo rootstock were grafted with three buds from either $C \operatorname{Las}(+)$ (treatment) or $C \operatorname{Las}(-)$ (control) Lisbon lemon or Washington navel orange source plants. The $C$ Las(+) material was originally sourced from Hacienda Heights, CA. A total of 11 control and 11 treatment lemon plants and six control and six treatment orange plants were sampled for transcriptomics, proteomics, metabolomics, and micronutrient analysis over the course of 46 weeks (February 2014 to January 2015). Plant IDs were arbitrarily chosen numbers.

\section{Quantitative polymerase chain reaction (qPCR) detection of CLas}

CLas presence was confirmed by qPCR assay of petiole samples, with the first sample collected at 10 weeks postgrafting (wpg) and subsequent samples collected monthly thereafter. DNA was extracted from $200 \mathrm{mg}$ of midrib and petioles obtained from six to eight leaves per plant using the Qiagen MagAttract Plant DNA extraction kit (Qiagen, Valencia, CA). qPCR was performed using the USDA-APHIS-PPQ protocol using the HLBas and HLBr primers and HLBp probe for CLas detection with $\mathrm{COX}$ primers and probe as the positive internal control (Bash et al. 2012; Li et al. 2006). A tree was considered to be $C$ Las(+) ("positive" for $C$ Las) if the cycle threshold $(\mathrm{Ct})$ was $<37$ (based on the USDA-APHIS guidelines [Bash et al. 2012; Li et al. 2006]) at more than one time point.

\section{Transcriptomics}

Total RNA was extracted and used as input for polyA enrichment for stranded cDNA library preparation. PE100 sequencing was performed using an Illumina HiSeq3000 system. The raw RNA sequencing (RNA-seq) reads were filtered for rRNA, chloroplast, and mitochondrial genes before quality screening. Quality-trimmed RNA-seq reads were mapped to $C$. sinensis v2.0 (Xu et al. 2013) genes using HISAT2 (Kim et al. 2015), and counts were generated using StringTie (Pertea et al. 2015). edgeR (Anders and Huber 2010) was used to identify differentially expressed genes between CLasinfected and control grafted plants at each time point (false discovery rate $<0.05$ and $\log 2$ FoldChangel $\geq 1$ ). Gene ontology enrichment was performed using the $C$. sinensis v2 metabolic pathway database (http://ptools.citrusgenomedb.org/) (Flores-Gonzalez et al. 2019). The navel and lemon sequencing data were deposited to GenBank and can be accessed using the BioProject IDs PRJNA417324 and PRJNA348468, respectively.

\section{Proteomics}

Protein was extracted from ground leaf material by precipitating overnight using $10 \%$ trichloroacetic acid in acetone with 
$2 \% \beta$-mercaptoethanol $(10 \mathrm{ml} / \mathrm{mg}$ of wet leaf weight). The protein pellet was washed and resuspended in triethylammonium bicarbonate. Protein concentration was measured using the BioRad Quick Start Bradford Protein Assay (Bio-Rad Laboratories, Hercules, CA). Samples were reduced by addition of tris-carboxyethyl phosphine to protein samples, and cysteine alkylation was performed by addition of iodoacetamide before trypsin digestion. C18 column cleanup (Waters Sep-Pak C18 1cc) was performed on the trypsin-digested samples before liquid chromatography-mass spectrometry analysis. The SI Methods contain the liquid chromatography tandem mass spectrometry parameters used for analysis of the proteome. Mascot Daemon 2.3.2 (Matrix Science, Boston, MA) was used to search the data files (Mascot generic format) against a citrus protein database containing proteins predicted from the $C$. clementina v1.0, C. sinensis v1.1, and CLas genomes. The mass spectrometry proteomics data have been deposited to the ProteomeXchange Consortium (Vizcaíno et al. 2014) via the PRIDE partner repository (Vizcaíno et al. 2013) with the dataset identifiers PDX006316, PXD005905, PXD006010, and PXD006011. All proteomics data are MIAPE (minimum information about a proteomics experiment) compliant.

\section{Metabolomics}

Sample preparation, ${ }^{1} \mathrm{H}$ nuclear magnetic resonance (NMR) data acquisition, spectral processing, and metabolite identification and quantification were performed as described in Chin et al. (2019). Briefly, 15 to 25 leaf disks (6.35-mm diameter) were taken from leaves, pooled, freeze dried (Labconco FreeZone Plus), and ground (BioSpec Mini-Beadbeater-16). The sample was extracted in phosphate buffer (10 mM, pH 6.8), mixed for $15 \mathrm{~min}$ at $90^{\circ} \mathrm{C}$ (Eppendorf ThermoMixer C), and centrifuged to pellet the leaf material. The resulting supernatant was collected and centrifuged; $585 \mu \mathrm{l}$ of the supernatant was collected, and $65 \mu \mathrm{l}$ of internal standard containing $5 \mathrm{mM} 3$-(trimethylsilyl)-1propanesulfonic acid- $d_{6}$ was added. Then, $600 \mu$ of the mixture was added to 5-mm NMR tubes. NMR data acquisition parameters are provided in the SI Methods. Targeted metabolite identification and quantification was conducted using Chenomx NMR suite v7.6 (Chenomx, Edmonton, AB, Canada). Orthogonal partial least squares (OPLS) analysis was performed in SIMCA v13.0.3. ${ }^{1} \mathrm{H}$ NMR spectra have been deposited to https:// citrusgreening.org/metabolomics_host/index.

\section{ICP-MS}

Fresh, frozen leaves were ground in liquid nitrogen using a mortar and pestle. A minimum of $25 \mathrm{mg}$ of the frozen, ground leaf tissue was freeze dried for $48 \mathrm{~h}$ (Labconco FreeZone Plus). Then, $500 \mu \mathrm{l}$ of $50 \% \mathrm{HNO}_{3}$ was added to $25 \mathrm{mg}$ of sample, and samples (including a method blank and a digestion quality control standard) were incubated for $2 \mathrm{~h}$ at room temperature, followed by $1 \mathrm{~h}$ at $95^{\circ} \mathrm{C}$. Then, $250 \mu \mathrm{l}$ of concentrated trace metals grade $\mathrm{HNO}_{3}$ (Fisher Scientific, Hampton, NH) was added, and samples were incubated at $95^{\circ} \mathrm{C}$ for an additional $1 \mathrm{~h}$. After samples were cooled to room temperature, $650 \mu$ of $30 \% \mathrm{H}_{2} \mathrm{O}_{2}$ (J.T. Baker) was added in five increments $(3 \times 100 \mu \mathrm{l} ; 1 \times 150 \mu \mathrm{l}, 1 \times 200 \mu \mathrm{l})$ with heating to $95^{\circ} \mathrm{C}$ between additions. After the final aliquot, samples were incubated at $95^{\circ} \mathrm{C}$ for $3 \mathrm{~h}$, allowed to cool, and diluted with $8.3 \mathrm{ml}$ of $18.2 \mathrm{M} \Omega / \mathrm{cm}$ water (EMD Millipore, Billerica, MA) prior to analysis by the Interdisciplinary Center for Plasma Mass Spectrometry at the University of California at Davis (http://icpms.ucdavis.edu/) using an Agilent 8900 ICP-MS (Agilent Technologies, Palo Alto, CA).

\section{RESULTS}

Here, we compare the changes in transcript, protein, metabolite, and micronutrient abundance in HLB-tolerant Lisbon lemon (C. limon) and HLB-susceptible Washington navel $(C$. sinensis) greenhouse plants graft inoculated with $C$ Las during the early stages of infection. At $10 \mathrm{wpg}$, one navel (no. 32) and two lemons (nos. 61 and 75) tested $C$ Las(+) via qPCR. By the end of the study (46 wpg), 6/11 of the treatment lemon plants (nos. 39, 57, 61, 64, 75, and 78) and 4/6 of the navel plants (nos. 9, 10, 25, and 32) had $\mathrm{Ct}<37$ at multiple time points; these plants were considered $C$ Las $(+)$ and were used for further analyses (Table 1; Supplementary Table S1). Of the control plants, 4/6 navel (nos. 17, 35, 30, and 34), and 11/11 lemon had Ct values of 40 throughout the experiment and were also used in analysis. Two control navel trees had weakly positive $\mathrm{Ct}$ values at $40 \mathrm{wpg}$, likely due to contamination during sample preparation. Retesting the exact same DNA samples yielded $C \operatorname{Las}(-)$ results $(\mathrm{Ct}=40)$, and these trees never developed HLB symptoms. Nonetheless, these two plants were excluded from analyses as a precaution. The lemon control plants used for transcriptomic, proteomic, and micronutrient analyses were randomly selected to match the number of $C$ Las(+) plants analyzed, whereas all 11 control lemon plants were used for metabolomic analysis.

HLB symptoms were apparent in all but one of the CLas(+) trees (lemon no. 57) by the end of the study (Table 1; Supplementary Table S1). Symptoms included yellow leaf mottle, leaf deformities, and/or poor plant vigor. One $C$ Las-graft-inoculated lemon plant (no. 66) never tested CLas(+) by qPCR but showed HLB symptoms by 26 wpg (Supplementary Table S1). The first time point at which HLB symptoms appeared was 16 wpg for lemon plant number 61 and $22 \mathrm{wpg}$ for navel plant number 32 (Table 1, Supplementary Fig. S1). Of the other CLas(+) plants, three lemons began to show HLB symptoms between 20 and 22 wpg and two navels by 26 wpg. One graft-inoculated infected lemon (no. 64) and one navel (no. 25) did not develop visual symptoms until $40 \mathrm{wpg}$.

Sampling strategy for transcriptomic, proteomic, metabolomic, and micronutrient analyses of navel and lemon samples are summarized in Figure 1. Transcriptomic and proteomic analyses were conducted at time points prior to symptom development for both varieties (lemon: 2,10, and $14 \mathrm{wpg}$; navel: 8 and $18 \mathrm{wpg}$ ), as well as two time points after symptom development for the navels (26 and $46 \mathrm{wpg}$ ). Micronutrient analysis was performed at 10 and $14 \mathrm{wpg}$ for lemons and 8 and $18 \mathrm{wpg}$ for navels. Samples for metabolomics were collected throughout the experiment for both varieties and included weeks $2,8,10,12,14,16,18,20,22$, and 46. Our objective was to compare the Lisbon lemon and navel orange response to CLas infection prior to HLB symptom development. Because the time points selected for lemon and navel transcriptomics, proteomics, and micronutrient profiling were not identical, we focused our comparative analyses on 10 and $14 \mathrm{wpg}$ for lemons and 8 and $18 \mathrm{wpg}$ for navels. Longitudinal analyses for the lemon and navel oranges are reported separately (Chin et al. 2019; Ramsey et al. 2020).

To determine if $C$ Las infection impacted plant micronutrient status, we profiled the leaf micronutrients of both citrus varieties. Although we observed some differences in micronutrient concentrations between lemons and navel oranges, these differences failed to reach statistical significance (Mann-Whitney $\mathrm{U}, P>$ 0.05). Higher concentrations of several micronutrients were observed in CLas(+) lemon leaves, and to a lesser extent in $C$ Las(+) navel orange leaves, relative to controls prior to symptom manifestation (Fig. 2, Supplementary Dataset S1). At 
10 wpg in lemon and 8 wpg in navel orange, both $\mathrm{Cu}^{2+}$ and $\mathrm{K}^{+}$ were higher in $C$ Las (+) plants compared with controls, whereas $\mathrm{Ca}^{2+}$ was lower. The fold change for all three micronutrients was smaller for navels when compared with that of lemons (Fig. 2). $\mathrm{Zn}^{2+}$ and $\mathrm{Fe}^{2+}$ levels were lower in $C$ Las(+) navels at 8 wpg but were higher at $10 \mathrm{wpg}$ in lemons (Fig. 2). At $14 \mathrm{wpg}$, all micronutrients except $\mathrm{Cu}^{2+}$ were higher in concentration in $C \mathrm{Las}(+)$ lemons compared with controls. At $18 \mathrm{wpg}, \mathrm{Mg}^{2+}, \mathrm{Cu}^{2+}$, $\mathrm{Fe}^{2+}$, and $\mathrm{Ca}^{2+}$ were lower in concentration, and $\mathrm{K}+$ higher in concentration, in infected navels relative to controls.

RNA-seq analysis of navel leaves revealed that 378, 18, 1,922, and 2,390 genes were differentially expressed at 8, 18, 26, and 46 wpg, respectively (Supplementary Dataset S2). A total of 248 proteins were found to be differentially abundant between leaves of $C \operatorname{Las}(+)$ and $C \operatorname{Las}(-)$ trees at one or more time points, with 96, 88,138 , and 138 proteins differentially abundant between control and infected navels at 8, 18, 26, and $46 \mathrm{wpg}$, respectively (Supplementary Dataset S3). Changes to the metabolome between control and infected plants could be observed using OPLS discriminant analysis, although differences for individual metabolites failed to reach statistical significance (analysis of covariance, using baseline as the covariate). Visualization of the metabolome for the time points prior to symptom development ( 2 to $18 \mathrm{wpg}$ ) revealed that sugars, amino acids, and other compounds were higher in CLas(+) navels compared with controls (Fig. 3A). Important metabolites for separation of navels during early infection (variable important to the projection [VIP] $>1$ ) included the amino acids asparagine, aspartate, proline, and proline betaine, and the nucleotides uridine and cytidine, as well as trigonelline and synephrine.

In the lemon plants, 231 genes were differentially expressed at baseline, 2, 10, and $14 \mathrm{wpg}$, respectively (Supplementary Dataset $\mathrm{S} 2$ ). A total of 106 unique proteins were differentially abundant in lemon leaves, with 6,85 , and 29 proteins differentially abundant between control and infected lemons at 2, 10, and $14 \mathrm{wpg}$, respectively (Supplementary Dataset S3). In contrast to the navels, metabolome differences between infected and control lemons could not be identified prior to symptom development (16 wpg).

Similar findings in symptomatic plants at the metabolite level were observed when comparing navels and lemons. A clear difference in the metabolome was observed between CLas(+) navels and controls after symptom expression (22 and $46 \mathrm{wpg}$ ) (Fig. 3B). Although no gene expression or protein data were collected at symptomatic lemon time points, metabolome differences between infected and control lemons were identified (22 and 46 wpg), but these changes were not as substantial as that of the navels at the same time points (Fig. 3B; Supplementary
Dataset S4). According to the VIP, important metabolites (VIP > 1) for separation of $C \operatorname{Las}(+)$ navels or lemons from controls included the amino acids arginine, asparagine, proline, and proline betaine, the nucleotides uridine and cytidine, as well as

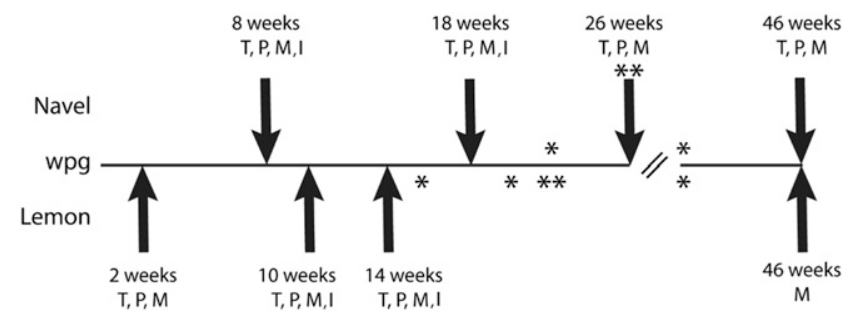

FIGURE 1

Overview of the time points (weeks postgrafting [wpg]) when transcriptomic ( $T$, RNA sequencing), proteomic ( $P$, tandem mass spectrometry), metabolomic $\left(\mathrm{M},{ }^{1} \mathrm{H}\right.$ nuclear magnetic resonance), and micronutrient ( $\mathrm{I}$, inductively coupled plasma mass spectrometry) analyses were conducted for navel and lemon plants. Metabolomics analysis was also conducted (every 2 weeks from 2 to $22 \mathrm{wpg}$, with the exception of 4 and $6 \mathrm{wpg}$, and at $46 \mathrm{wpg}$ ). Asterisks represent when a plant was first observed to have symptoms.

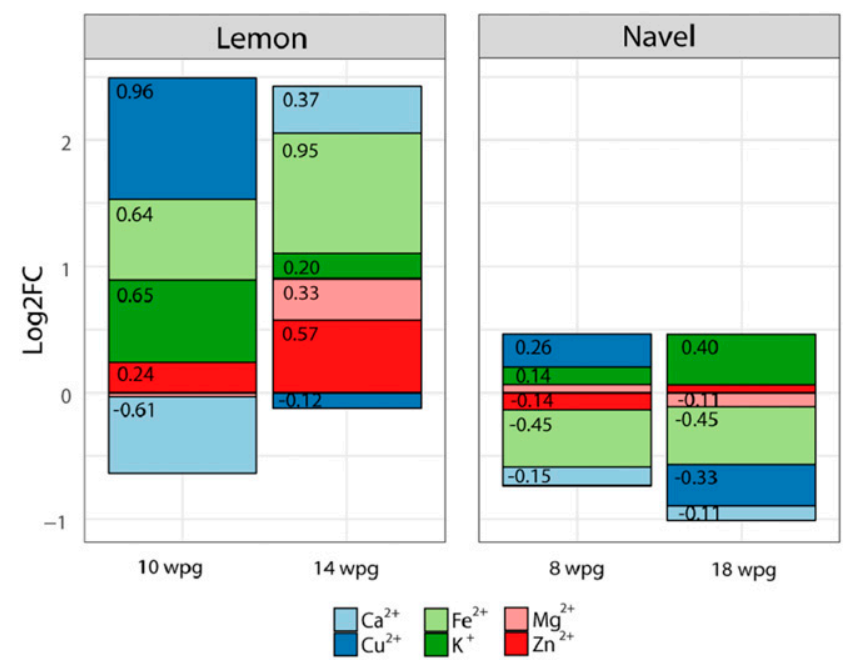

FIGURE 2

Log2FoldChange (Log2FC) of the median concentrations of micronutrients ('Candidatus Liberibacter asiaticus'-positive relative to control) for lemon (10 and 14 weeks postgrafting [wpg]) and navel (8 and $18 \mathrm{wpg})$ plants.

TABLE 1

Quantitative polymerase chain reaction cycle threshold (Ct) values for lemon and navel plants graft inoculated with 'Candidatus Liberibacter asiaticus' (CLas) used in analyses $^{\mathrm{a}}$

\begin{tabular}{|c|c|c|c|c|c|c|c|c|c|}
\hline \multirow[b]{2}{*}{ Variety } & \multirow[b]{2}{*}{ ID } & \multicolumn{7}{|c|}{ Weeks postgrafting (wpg) } & \multirow[b]{2}{*}{ Symptom appearance } \\
\hline & & 10 & 16 & 22 & 30 & 35 & 40 & 46 & \\
\hline \multirow[t]{6}{*}{ Lemon } & 39 & 40 & 40 & 40 & 22 & 27.1 & 39.9 & 40 & $22 \mathrm{wpg}$ \\
\hline & 57 & 39.2 & 31.7 & 30 & 40 & 24.3 & 39.4 & 40 & Uncertain by $46 \mathrm{wpg}$ \\
\hline & 61 & 25.6 & 26.2 & 35.2 & 23 & 27.2 & 22.1 & 23.3 & $16 \mathrm{wpg}$ \\
\hline & 64 & 40 & 40 & 30.9 & 30.6 & 31.2 & 26.9 & 25.6 & $40 \mathrm{wpg}$ \\
\hline & 75 & 25.4 & 29.3 & 24.5 & 24.5 & 24.1 & 22.4 & 23.6 & $22 \mathrm{wpg}$ \\
\hline & 78 & 37.9 & 30.4 & 39.5 & 23.6 & 22.9 & 22.7 & 24.2 & $20 \mathrm{wpg}$ \\
\hline \multirow[t]{4}{*}{ Orange } & 9 & 40 & 40 & 40 & 26.91 & 25.86 & 35.77 & 20.77 & $26 \mathrm{wpg}$ \\
\hline & 10 & 40 & 40 & 33.74 & 31.79 & 20.97 & 20.36 & 19.38 & $26 \mathrm{wpg}$ \\
\hline & 25 & 40 & 31.16 & 40 & 40 & 26.16 & 25.07 & 22.63 & $40 \mathrm{wpg}$ \\
\hline & 32 & 23.15 & 23.87 & 26.61 & 32.37 & 23.39 & 20.53 & 21.04 & $22 \mathrm{wpg}$ \\
\hline
\end{tabular}

${ }^{a}$ A plant was considered $C \operatorname{Las}(+)$ if the measured $\mathrm{Ct}$ value was less than 37 (bold) at multiple time points. In the event that $\mathrm{Ct}>37$ at all time points, the tree was considered CLas(-). 
choline, synephrine, fructose, and an unknown compound with chemical shifts similar to limonin.

Several types of proteins involved in plant defense were induced during infection (Fig. 4). Transcripts for chitin degradation were upregulated at $14 \mathrm{wpg}$ in $C \operatorname{Las}(+)$ lemons (Supplementary Table S2), but there was little change at the protein level (Fig. 4). Higher abundance of chitin degradation proteins was observed in infected navel leaves at 8 and 18 wpg compared with controls,
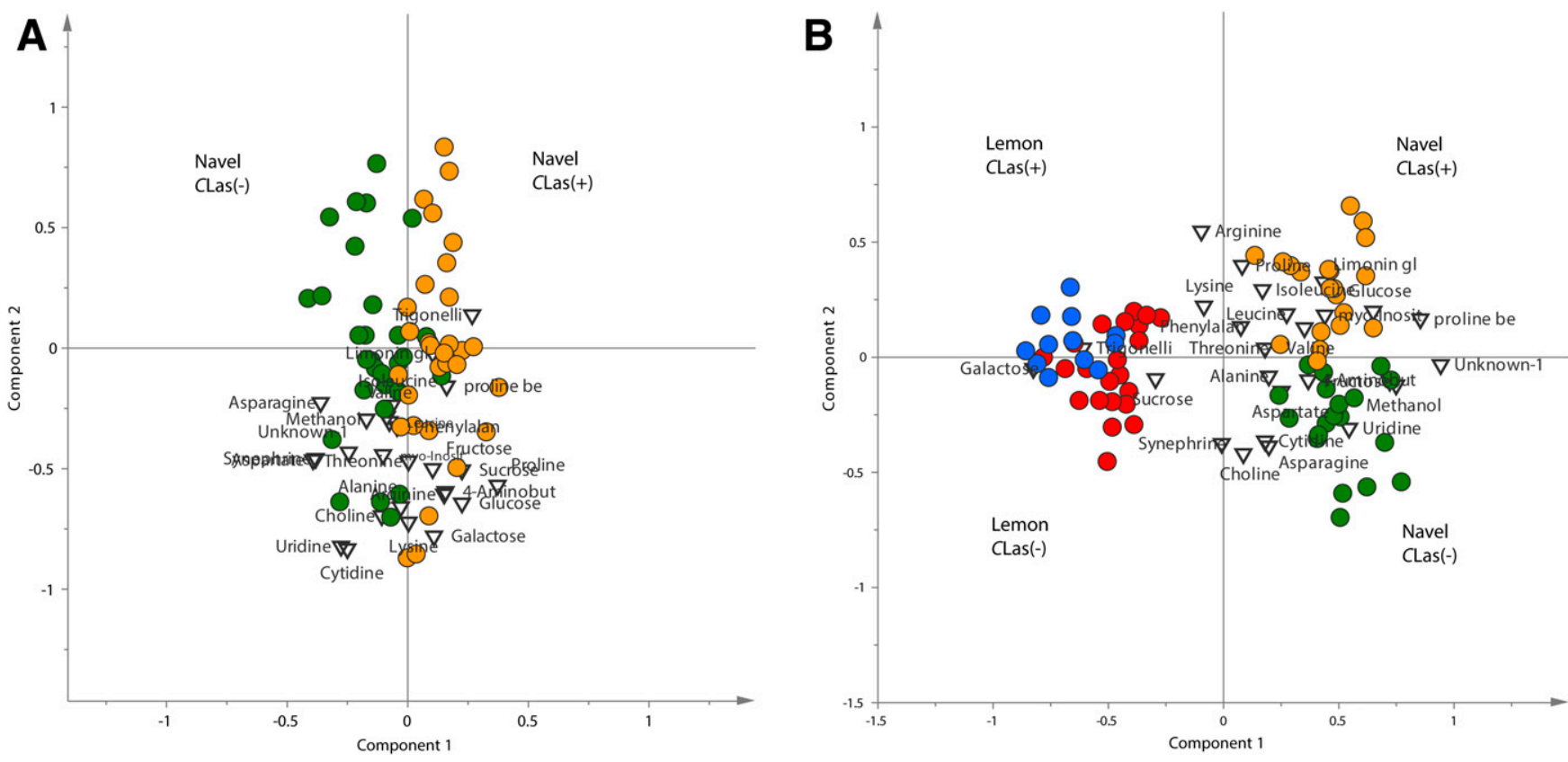

FIGURE 3

The impact of 'Candidatus Liberibacter asiaticus' (CLas) on the navel and lemon metabolome. A, Orthogonal partial least squaresdiscriminant analysis (OPLS-DA) biplot of control (green circles) and CLas(+) (yellow circles) navel leaves from 2 to 18 weeks postgrafting (wpg), and metabolites (inverted triangles) contributing to class discrimination. $R^{2}=0.577 ; \mathrm{Q}^{2}=0.300$. ANOVA of the cross-validated residuals $P=0.003$. B, OPLS-DA biplot of lemon and navel leaves at 22 and $46 \mathrm{wpg}$, and metabolites (inverted triangles) contributing to class discrimination. $R^{2}=0.687 ; Q^{2}=0.503$. ANOVA of the cross-validated residuals $P=4 \times 10^{-20}$.

A

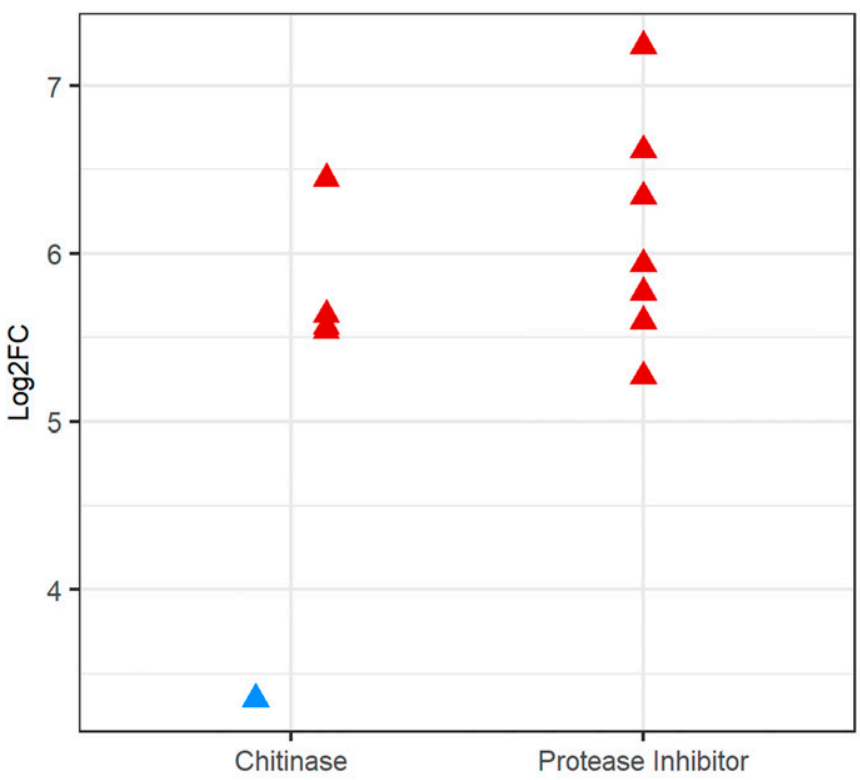

B

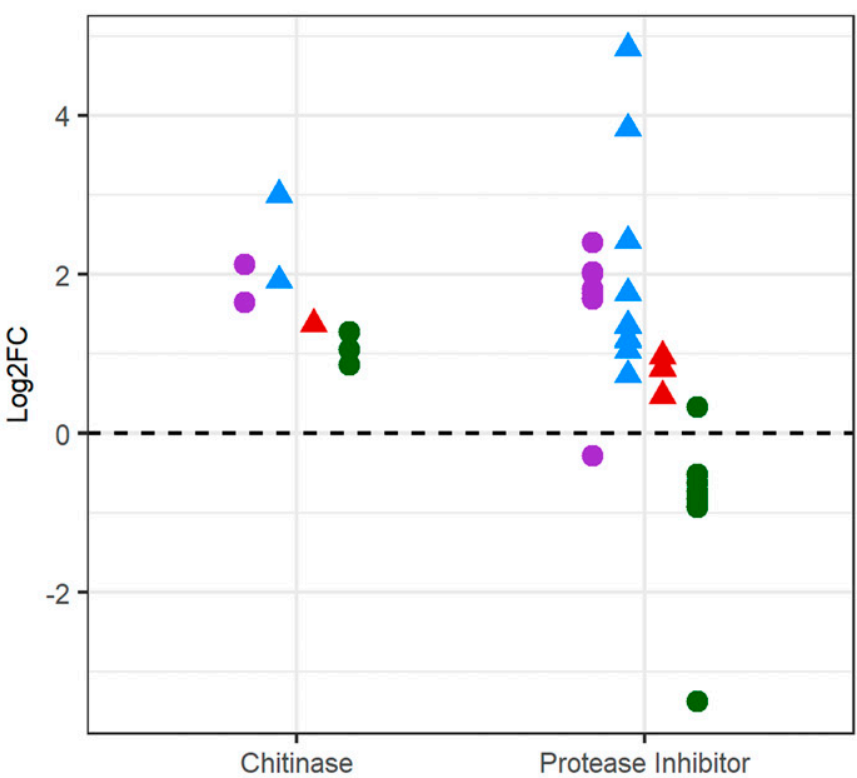

Navel, 18 wpg

FIGURE 4

Overview of the Log2FoldChange (Log2FC) (infected relative to control) of transcripts $(\mathbf{A})$ and protein (B) related to protease inhibitors (Kunitz trypsin and protease inhibitors, serine protease inhibitor) and chitinases 8 (purple), and 18 (green) weeks postgrafting (wpg) for navels and 10 (blue), and 14 (red) wpg for lemons. 
although there was no difference at the transcript level. Although transcripts for protease inhibitors (PIs, which include both Kunitz family PIs and serine PIs) were highly upregulated at $14 \mathrm{wpg}$ in lemons, there were no differences at $10 \mathrm{wpg}$ for lemons, nor for any time point for navels (Fig. 5). However, PI proteins were differentially abundant in both varieties (Supplementary Dataset S3). Most had higher abundance in $C \operatorname{Las}(+)$ navels at $8 \mathrm{wpg}$ and CLas(+) lemons at 10 and 14 wpg compared with controls (Fig. 4); however, the differentially abundant PIs at 18 wpg had lower abundance in infected navels relative to controls.

Few photosynthesis-related genes were differentially expressed for both lemon and navels (Supplementary Dataset S2), but many photosynthesis proteins were differentially abundant in both navels ( 8 and $18 \mathrm{wpg}$ ) and lemons (10 wpg). At $10 \mathrm{wpg}$ in lemons, lightreaction proteins had higher abundance relative to controls, whereas dark-reaction proteins had lower abundance (Fig. 5). Light- and dark-reaction proteins were not differentially abundant at $14 \mathrm{wpg}$, although gene expression for two chlorophyllases, which degrade chlorophyll, were upregulated at $14 \mathrm{wpg}$ in lemons, indicating some disruption of photosynthesis (Supplementary Dataset S2). In navels at $8 \mathrm{wpg}$, most light-reaction proteins had lower abundance relative to controls, and few dark-reaction proteins were differentially abundant at this time point. At $18 \mathrm{wpg}$, there was no consistent pattern in abundance of light-reaction proteins in CLas(+) navels relative to controls, and all differentially abundant dark-reaction proteins had lower abundance in infected plants compared with controls (Fig. 5).

Upregulation of carbohydrate metabolism has been reported during CLas infection both pre- and post-symptom development (Nwugo et al. 2013a, 2013b; Rawat et al. 2015). We observed the

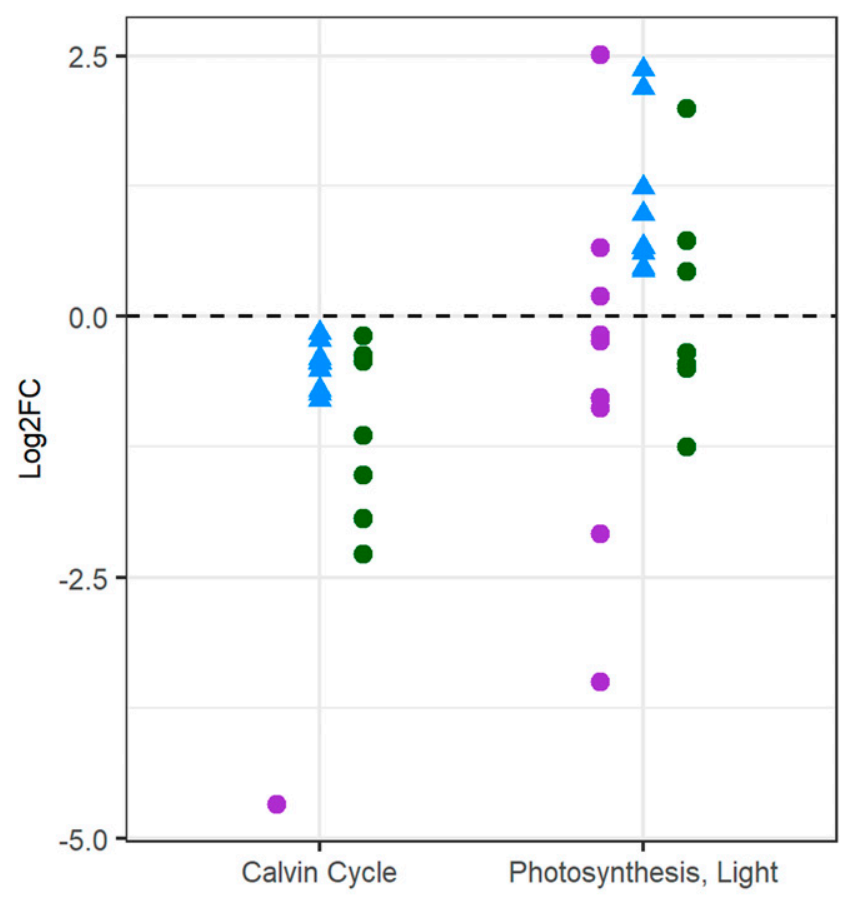

\footnotetext{
Navel, 8 wpg $\Delta$ Lemon, 10 wpg Navel, 18 wpg

\section{FIGURE 5}

The Log2FoldChange (Log2FC) in protein abundance for lightreaction and dark-reaction photosynthesis proteins in navels and lemons (infected relative to control) at 8 (purple), and 18 (green) weeks postgrafting (wpg) for navels and 10 (blue) wpg for lemons. There were no photosynthesis-related proteins differentially abundant at 14 wpg for lemons.
}

overall concentration of the sugars glucose, sucrose, and galactose to be higher in $C$ Las(+) plants of both navels and lemons from 10 to $14 \mathrm{wpg}$ compared with controls (Fig. 6). Proteins involved in glycolytic processes had lower abundance in CLas(+) lemons at $10 \mathrm{wpg}$ and in $C \operatorname{Las}(+)$ navels at $18 \mathrm{wpg}$ (Supplementary Dataset S3).

\section{DISCUSSION}

We compared the response of CLas-tolerant (lemon) and $C$ Las-susceptible (navel) varieties over time. In agreement with other studies (Albrecht et al. 2014), we observed that the rate of $C$ Las transmission via grafting was lower in the tolerant lemons, with approximately half of the plants testing positive for CLas, compared with the navels, for which two-thirds of the plants became positive for $C$ Las. HLB symptoms can be easily confused with those of nutrient deficiencies, and it is thought that susceptibility to the disease may increase with poor plant nutrition (Spann and Schumann 2009). There have been inconsistent findings regarding whether foliar applications of micronutrients to HLB-affected trees increase productivity, which may be due to the micronutrients used, the concentration, and the application frequency (Morgan et al. 2016).

The overall magnitude of difference in leaf micronutrient concentration between control and infected lemons was larger than that for navels. The concentrations of iron, potassium, and zinc were higher in $C \operatorname{Las}(+)$ lemon leaves compared with controls prior to symptom manifestation at weeks 10 and 14 . Similarly, $\mathrm{K}^{+}$concentration was higher in infected navels at both 8 and 18 wpg compared with controls, but in contrast to lemons, $\mathrm{Fe}^{2+}$ concentration was lower in infected navels. Potassium deficiency causes symptoms similar to HLB, including smaller leaf size, leaf mottling, leaf drop, leaf necrosis, chlorosis, twig dieback, and fruit drop (Chapman 1968). Others have reported accumulation of potassium in symptomatic CLas(+) lemons (Nwugo et al. 2013a) as well as symptomatic and presymptomatic grapefruit (Nwugo et al. 2013b), although the difference between infected and controls was marginal and only significant for control and symptomatic grapefruits. Potassium is required to maintain cell wall integrity, and maintenance of the cell wall barrier may be an essential first line of defense. Although potassium was higher in both infected navels and lemons, transcripts for cell wall macromolecule catabolic processes were upregulated at $14 \mathrm{wpg}$ in lemons (Supplementary Table S2), which might suggest cell wall disruption.

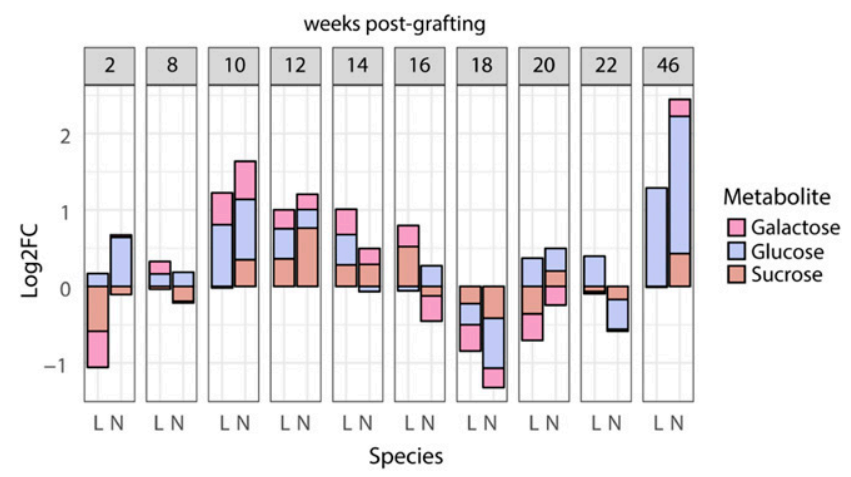

FIGURE 6 Log2FoldChange (Log2FC) of median carbohydrate concentration ('Candidatus Liberibacter asiaticus'-positive relative to control) for lemons $(\mathrm{L})$ and navels $(\mathrm{N})$ at the indicated weeks. 


\section{CLas disrupts plant defense}

Plants exhibit a variety of defense mechanisms to protect against pathogens (Chisholm et al. 2006). One such mechanism is the use of PIs, which generally are involved in plant defense against bacteria, viruses, and insects (Haq et al. 2004; Kim et al. 2009). Others have shown upregulation of transcripts for the Kunitz family of trypsin inhibitors and PIs, as well as miraculinlike proteins (which have sequence similarity to Kunitz family trypsin inhibitors and PIs [Selvakumar et al. 2011; Tsukuda et al. 2006]) in CLas(+) rough lemon and sweet oranges at 5 wpg (Fan et al. 2012) and Cleopatra mandarins (Bowman and Albrecht 2015), as well as in asymptomatic and symptomatic oranges (Fan et al. 2011; Fu et al. 2016). Although we observed changes in PI protein abundance in both navels and lemons prior to symptom manifestation, only lemons at $14 \mathrm{wpg}$ had a coordinated response at the transcript level. A CLas effector, SDE1, has been reported to inhibit citrus papain-like cysteine proteases that play a role in plant defense (Clark et al. 2018; Pitino et al. 2016; Prasad et al. 2016). It is unknown whether SDE1 actually impacts citrus PI levels, but these results suggest that $C$ Las may have the ability to impact the production of PIs in citrus.

Chitin is a polysaccharide ( $N$-acetyl-glucosamine polymer) present in insects and fungi (Sánchez-Vallet et al. 2015; Zhu et al. 2016). Transcripts for chitin degradation were upregulated at 14 wpg in CLas(+) lemon leaves, and proteomic data indicated higher abundance of these proteins in infected plants. Previously, lower protein abundance and higher transcript levels of chitinase were reported in symptomatic lemons (Nwugo et al. 2013a) and Valencia oranges (Albrecht and Bowman 2008). It is unclear how chitinase would impact CLas colonization of citrus, but its upregulation could be related to changes in fungal communities on the leaves (Busby et al. 2016; Wang et al. 2017a).

\section{Photosynthesis}

CLas infection had posttranslational effects on chloroplast regulation, consistent with previous reports that CLas effector proteins localize to and function within the chloroplast (Pitino et al. 2018). Differential expression of a few photosynthesisrelated genes prior to symptom development was observed in both navels and lemons. Many photosynthesis proteins were differentially abundant in both varieties, with more proteins differentially abundant in presymptomatic navels compared with lemons (Fig. 5). Although regulation of light-reaction proteins was mixed in navels, these proteins were consistently in higher abundance in lemons at $10 \mathrm{wpg}$, and dark-reaction proteins were in lower abundance for infected plants of both varieties. Downregulation of photosynthesis genes has been reported by others in Madam Vinous sweet orange at $17 \mathrm{wpg}$ (Fan et al. 2012). Chlorophyll catabolism gene expression was upregulated at $14 \mathrm{wpg}$ in lemons (Supplementary Table S2), indicating some disruption of photosynthesis in lemons. One reason for the difference between the lemon and navel response may be related to $\mathrm{Fe}^{2+}$ concentration. Although infected lemons accumulated $\mathrm{Fe}^{2+}$ relative to controls, infected navels had lower concentrations. Indeed, ferritin proteins had higher abundance at 10 and 14 wpg in lemons but lower abundance at $18 \mathrm{wpg}$ in navels, and they were not differentially abundant at $8 \mathrm{wpg}$ (Supplementary Dataset $\mathrm{S} 3$ ). $\mathrm{Fe}^{2+}$ is required for photosynthesis, and deficiency has been shown to disrupt chlorophyll synthesis and photosystem I function (López-Millán et al. 2016). Most photosystem proteins had lower abundance at $8 \mathrm{wpg}$, but these changes did not translate into observable symptoms at that time point. Nwugo et al. (2013b) also found a correlation between lower micronutrient concentration and lower abundance of photosynthesis-related proteins in infected grapefruit relative to controls, which did not translate into earlier symptom development either. Accumulation of iron in lemons may help keep photosynthesis pathways functional and may play a role in CLas tolerance by ensuring adequate energy production.

Photosynthesis is directly related to carbohydrate metabolism, and upregulation of carbohydrate metabolism has been reported during CLas infection both pre- and post-symptom development (Nwugo et al. 2013a, 2013b; Rawat et al. 2015). Here, the overall concentrations of the sugars sucrose, glucose, and galactose were higher in CLas(+) plants of both varieties from 10 to $14 \mathrm{wpg}$ compared with controls (Fig. 6). Higher concentrations of glucose can lead to feedback inhibition of photosynthesis, which could also explain the lower abundance of photosynthesis-related proteins described above. CLas infection in citrus has been reported to have numerous effects on $D$. citri, such as enhancing long-distance flights (Martini et al. 2015) and increasing fecundity (Pelz-Stelinski and Killiny 2016), vector manipulation phenotypes which may be indirectly related to an increase in phloem sugar content.

\section{CONCLUSION}

In general, lemons are reported to be more tolerant to CLas compared with sweet oranges (Folimonova et al. 2009; Martinelli et al. 2016). Our findings suggest that $C$ Las induces disruption of citrus host metabolism in both susceptible (Washington navel) and tolerant (Lisbon lemon) varieties that can be detected at the transcript, protein, metabolite, and micronutrient level. There were several key differences between the two varieties presymptomatically that included a heightened response to CLas infection in the susceptible navel variety compared with the more tolerant lemon variety. Photosynthesis was less affected in presymptomatic lemons compared with navels, and micronutrients accumulated in presymptomatic $C \operatorname{Las}(+)$ lemons compared with navels. PI transcripts were highly upregulated in lemons just prior to symptom development, but not in navels. Additionally, although major changes in the navel leaf metabolome were observed at both presymptomatic and symptomatic time points, the overall lemon leaf metabolome did not appear to be as severely affected by infection, despite earlier symptom manifestation. Although the time points compared between the two varieties were not identical, the findings presented here further our understanding of presymptomatic differences for susceptible and more tolerant citrus varieties, and have helped define unique and common responses in these varieties. The information presented here may be important for developing varieties that are more tolerant to CLas, especially in California, because the majority of fruit grown commercially is for fresh consumption.

\section{ACKNOWLEDGMENTS}

We gratefully acknowledge Tiffany Simpson for help with greenhouse maintenance at the Contained Research Facility, and Steve Stearns and Anna Skomal for metabolomics sample preparation. We thank Dr. Cynthia Levesque for performing qPCR on the leaf samples.

\section{LITERATURE CITED}

Albrecht, U., and Bowman, K. D. 2008. Gene expression in Citrus sinensis (L.) Osbeck following infection with the bacterial pathogen Candidatus Liberibacter asiaticus causing huanglongbing in Florida. Plant Sci. 175: 291-306.

Albrecht, U., and Bowman, K. D. 2012. Transcriptional response of susceptible and tolerant citrus to infection with Candidatus Liberibacter asiaticus. Plant Sci. 185-186:118-130. 
Albrecht, U., Hall, D. G., and Bowman, K. D. 2014. Transmission efficiency of Candidatus Liberibacter asiaticus and progression of huanglongbing disease in graft-and psyllid-inoculated citrus. HortScience 49:367-377.

Anders, S., and Huber, W. 2010. Differential expression analysis for sequence count data. Genome Biol. 11:R106.

Bash, J., Bulluck, R., da Graca, J., French, J. V., Gottwald, T., Halbert, S., Hall, D., Levy, L., Michalak, P., Polek, M., and Schubert, T. 2012. New Pest Response Guidelines Citrus Greening Disease. USDA, Washington DC.

Bové, J. M. 2006. Huanglongbing: A destructive, newly-emerging, centuryold disease of citrus. J. Plant Pathol. 88:7-37.

Bowman, K. D., and Albrecht, U. 2015. Comparison of gene expression changes in susceptible, tolerant and resistant hosts in response to infection with citrus tristeza virus and huanglongbing. J. Citrus Pathol. 2. Retrieved from https://escholarship.org/uc/item/5qt4z9c0.

Busby, P. E., Ridout, M., and Newcombe, G. 2016. Fungal endophytes: Modifiers of plant disease. Plant Mol. Biol. 90:645-655.

CDFA. 2012. Citrus disease huanglongbing detected in Hacienda Heights area of Los Angeles County. https://www.cdfa.ca.gov/egov/Press_Releases/ Press_Release.asp?PRnum=12-012 (accessed May 4, 2017).

Cevallos-Cevallos, J. M., Futch, D. B., Shilts, T., Folimonova, S. Y., and Reyes-De-Corcuera, J. I. 2012. GC-MS metabolomic differentiation of selected citrus varieties with different sensitivity to citrus huanglongbing. Plant Physiol. Biochem. 53:69-76.

Chapman, H. D. 1968. The mineral nutrition of citrus. Pages 200-247 in: The Citrus Industry: Anatomy, Physiology, Genetics, and Reproduction, Vol. II. W. Reuther, L. D. Batchelor, and H. J. Webber, eds. University of California, Division of Agricultural Sciences, Oakland, CA.

Chin, E. L., Ramsey, J. S., Mishchuk, D. O., Saha, S., Foster, E., Chavez, J. D., Howe, K., Zhong, X., Polek, M., Godfrey, K. E., Mueller, L. A., Bruce, J. E., Heck, M., and Slupsky, C. M. 2019. Longitudinal transcriptomic, proteomic, and metabolomic analyses of Citrus sinensis (L.) Osbeck graft-inoculated with 'Candidatus Liberibacter asiaticus'. J. Proteome Res. 19:719-732.

Chisholm, S. T., Coaker, G., Day, B., and Staskawicz, B. J. 2006. Hostmicrobe interactions: Shaping the evolution of the plant immune response. Cell 124:803-814.

Citrus Pest \& Disease Prevention Program. 2020. History of huanglongbing in California. https://californiacitrusthreat.org/wp-content/themes/citrus/files/pdf/ CP-152-0120-HLB-Timeline-Graphic_CCT-01.jpg (accessed March 8, 2020).

Clark, K., Franco, J. Y., Schwizer, S., Pang, Z., Hawara, E., Liebrand, T. W., Pagliaccia, D., Zeng, L., Gurung, F. B., and Wang, P. 2018. An effector from the huanglongbing-associated pathogen targets citrus proteases. Nat. Commun. 9:1718.

Dala-Paula, B. M., Plotto, A., Bai, J., Manthey, J. A., Baldwin, E. A., Ferrarezi, R. S., and Gloria, M. B. A. 2019. Effect of huanglongbing or greening disease on orange juice quality, a review. Front. Plant Sci. 9:1976.

Fan, J., Chen, C., Achor, D. S., Brlansky, R. H., Li, Z.-G., and Gmitter, F. G., Jr. 2013. Differential anatomical responses of tolerant and susceptible citrus species to the infection of 'Candidatus Liberibacter asiaticus'. Physiol. Mol. Plant Pathol. 83:69-74.

Fan, J., Chen, C., Yu, Q., Brlansky, R. H., Li, Z. G., and Gmitter, F. G. 2011. Comparative iTRAQ proteome and transcriptome analyses of sweet orange infected by "Candidatus Liberibacter asiaticus". Physiol. Plant. 143:235-245.

Fan, J., Chen, C., Yu, Q., Khalaf, A., Achor, D. S., Brlansky, R. H., Moore, G. A., Li, Z.-G., and Gmitter, F. G., Jr. 2012. Comparative transcriptional and anatomical analyses of tolerant rough lemon and susceptible sweet orange in response to 'Candidatus Liberibacter asiaticus' infection. Mol. Plant-Microbe Interact. 25:1396-1407.

Flores-Gonzalez, M., Hosmani, P. S., Fernandez-Pozo, N., Mann, M., Humann, J. L., Main, D., Heck, M., Brown, S., Mueller, L. A., and Saha, S. 2019. Citrusgreening.org: An open access and integrated systems biology portal for the huanglongbing (HLB) disease complex. bioRxiv 868364.

Folimonova, S. Y., Robertson, C. J., Garnsey, S. M., Gowda, S., and Dawson, W. O. 2009. Examination of the responses of different genotypes of citrus to huanglongbing (citrus greening) under different conditions. Phytopathology 99:1346-1354.

Fu, S., Shao, J., Zhou, C., and Hartung, J. S. 2016. Transcriptome analysis of sweet orange trees infected with 'Candidatus Liberibacter asiaticus' and two strains of citrus tristeza virus. BMC Genomics 17:349.

Gottwald, T. R. 2010. Current epidemiological understanding of citrus huanglongbing. Annu. Rev. Phytopathol. 48:119-139.

Gottwald, T. R., da Graça, J. V., and Bassanezi, R. B. 2007. Citrus huanglongbing: The pathogen and its impact. Plant Health Prog. 8:31.

Grafton-Cardwell, E. E., Godfrey, K. E., Rogers, M. E., Childers, C. C., and Stansly, P. A. 2005. Asian citrus psyllid. UCANR Publications. https:// escholarship.org/uc/item/8vr1376d (accessed January 18, 2016).

Grafton-Cardwell, E. E., Stelinski, L. L., and Stansly, P. A. 2013. Biology and management of Asian citrus psyllid, vector of the huanglongbing pathogens. Annu. Rev. Entomol. 58:413-432.
Haq, S. K., Atif, S. M., and Khan, R. H. 2004. Protein proteinase inhibitor genes in combat against insects, pests, and pathogens: Natural and engineered phytoprotection. Arch. Biochem. Biophys. 431:145-159.

Hijaz, F., Al-Rimawi, F., Manthey, J. A., and Killiny, N. 2020. Phenolics, flavonoids and antioxidant capacities in Citrus species with different degree of tolerance to huanglongbing. Plant Signal. Behav. 15:1752447.

Killiny, N. 2017. Metabolite signature of the phloem sap of fourteen citrus varieties with different degrees of tolerance to Candidatus Liberibacter asiaticus. Physiol. Mol. Plant Pathol. 97:20-29.

Killiny, N., Jones, S. E., Nehela, Y., Hijaz, F., Dutt, M., Gmitter, F. G., and Grosser, J. W. 2018. All roads lead to Rome: Towards understanding different avenues of tolerance to huanglongbing in citrus cultivars. Plant Physiol. Biochem. 129:1-10.

Kim, D., Langmead, B., and Salzberg, S. L. 2015. HISAT: A fast spliced aligner with low memory requirements. Nat. Methods 12:357-360.

Kim, J.-Y., Park, S.-C., Hwang, I., Cheong, H., Nah, J.-W., Hahm, K.-S., and Park, Y. 2009. Protease inhibitors from plants with antimicrobial activity. Int. J. Mol. Sci. 10:2860-2872.

Lee, J. A., Halbert, S. E., Dawson, W. O., Robertson, C. J., Keesling, J. E., and Singer, B. H. 2015. Asymptomatic spread of huanglongbing and implications for disease control. Proc. Natl. Acad. Sci. U.S.A. 112:7605-7610

Li, W., Hartung, J. S., and Levy, L. 2006. Quantitative real-time PCR for detection and identification of Candidatus Liberibacter species associated with citrus huanglongbing. J. Microbiol. Methods 66:104-115.

López-Millán, A. F., Duy, D., and Philippar, K. 2016. Chloroplast iron transport proteins-Function and impact on plant physiology. Front. Plant Sci. 7:178.

Martinelli, F., Reagan, R. L., Dolan, D., Fileccia, V., and Dandekar, A. M. 2016. Proteomic analysis highlights the role of detoxification pathways in increased tolerance to huanglongbing disease. BMC Plant Biol. 16:167.

Martini, X., Hoffmann, M., Coy, M. R., Stelinski, L. L., and Pelz-Stelinski, K. S. 2015. Infection of an insect vector with a bacterial plant pathogen increases its propensity for dispersal. PLoS One 10:e0129373.

McCollum, G., Hilf, M., Irey, M., Luo, W., and Gottwald, T. 2016. Susceptibility of sixteen citrus genotypes to 'Candidatus Liberibacter asiaticus'. Plant Dis. 100:1080-1086.

Morgan, K. T., Rouse, R. E., and Ebel, R. C. 2016. Foliar applications of essential nutrients on growth and yield of 'Valencia' sweet orange infected with huanglongbing. HortScience 51:1482-1493.

Nwugo, C. C., Duan, Y., and Lin, H. 2013a. Study on citrus response to huanglongbing highlights a down-regulation of defense-related proteins in lemon plants upon ' $\mathrm{Ca}$. Liberibacter asiaticus' infection. PLoS One 8: e67442.

Nwugo, C. C., Lin, H., Duan, Y., and Civerolo, E. L. 2013b. The effect of 'Candidatus Liberibacter asiaticus' infection on the proteomic profiles and nutritional status of pre-symptomatic and symptomatic grapefruit (Citrus paradisi) plants. BMC Plant Biol. 13:59.

Pelz-Stelinski, K., and Killiny, N. 2016. Better together: Association with 'Candidatus Liberibacter asiaticus' increases the reproductive fitness of its insect vector, Diaphorina citri (Hemiptera: Liviidae). Ann. Entomol. Soc Am. 109:371-376.

Pertea, M., Pertea, G. M., Antonescu, C. M., Chang, T.-C., Mendell, J. T., and Salzberg, S. L. 2015. StringTie enables improved reconstruction of a transcriptome from RNA-seq reads. Nat. Biotechnol. 33:290-295.

Pitino, M., Allen, V., and Duan, Y. 2018. Las $\Delta 5315$ effector induces extreme starch accumulation and chlorosis as $\mathrm{Ca}$. Liberibacter asiaticus infection in Nicotiana benthamiana. Front. Plant Sci. 9:113.

Pitino, M., Armstrong, C. M., Cano, L. M., and Duan, Y. 2016. Transient expression of Candidatus Liberibacter asiaticus effector induces cell death in Nicotiana benthamiana. Front. Plant Sci. 7:982

Pitino, M., Armstrong, C. M., and Duan, Y. 2017. Molecular mechanisms behind the accumulation of ATP and $\mathrm{H}_{2} \mathrm{O}_{2}$ in citrus plants in response to 'Candidatus Liberibacter asiaticus' infection. Hortic. Res. 4:17040.

Prasad, S., Xu, J., Zhang, Y., and Wang, N. 2016. SEC-translocon dependent extracytoplasmic proteins of Candidatus Liberibacter asiaticus. Front. Microbiol. 7:1989.

Ramsey, J. S., Chin, E., Chavez, J., Saha, S., Mishchuk, D., Mahoney, J., Mohr, J., Robinson, F., Mitrovic, E., Xu, Y., Strickler, S., Fernandez, N., Zhong, X., Polek, M., Godfrey, K., Giovannoni, J., Mueller, L., Slupsky, C., Bruce, J., and Heck, M. 2020. Longitudinal transcriptomic, proteomic, and metabolomic analysis of Citrus limon response to graft inoculation by 'Candidatus Liberibacter asiaticus'. J. Proteome Res. 19:2247-2263.

Rawat, N., Kiran, S. P., Du, D., Gmitter, F. G., and Deng, Z. 2015. Comprehensive meta-analysis, co-expression, and miRNA nested network analysis identifies gene candidates in citrus against huanglongbing disease. BMC Plant Biol. 15:184

Sánchez-Vallet, A., Mesters, J. R., and Thomma, B. P. 2015. The battle for chitin recognition in plant-microbe interactions. FEMS Microbiol. Rev. 39: $171-183$ 
Selvakumar, P., Gahloth, D., Tomar, P. P. S., Sharma, N., and Sharma, A. K. 2011. Molecular evolution of miraculin-like proteins in soybean Kunitz super-family. J. Mol. Evol. 73:369-379.

Spann, T. M., and Schumann, A. W. 2009. The role of plant nutrients in disease development with emphasis on citrus and huanglongbing. Proc. Fla. State Hort. Soc. 122:169-171.

Tsukuda, S., Gomi, K., Yamamoto, H., and Akimitsu, K. 2006. Characterization of cDNAs encoding two distinct miraculin-like proteins and stressrelated modulation of the corresponding mRNAs in Citrus jambhiri Lush. Plant Mol. Biol. 60:125-136.

Vizcaíno, J. A., Côté, R. G., Csordas, A., Dianes, J. A., Fabregat, A., Foster, J. M., Griss, J., Alpi, E., Birim, M., and Contell, J. 2013. The PRoteomics IDEntifications (PRIDE) database and associated tools: Status in 2013. Nucleic Acids Res.: D1063-D1069.

Vizcaíno, J. A., Deutsch, E. W., Wang, R., Csordas, A., Reisinger, F., Rios, D., Dianes, J. A., Sun, Z., Farrah, T., and Bandeira, N. 2014. ProteomeXchange provides globally coordinated proteomics data submission and dissemination. Nat. Biotechnol. 32:223-226.
Wang, N., Pierson, E. A., Setubal, J. C., Xu, J., Levy, J. G., Zhang, Y., Li, J., Rangel, L. T., and Martins, J., Jr. 2017b. The Candidatus Liberibacter-host interface: Insights into pathogenesis mechanisms and disease control. Annu. Rev. Phytopathol. 55:451-482.

Wang, N., Stelinski, L. L., Pelz-Stelinski, K. S., Graham, J. H., and Zhang, Y. 2017a. Tale of the huanglongbing disease pyramid in the context of the citrus microbiome. Phytopathology 107: 380-387.

Wang, Y., Zhou, L., Yu, X., Stover, E., Luo, F., and Duan, Y. 2016 Transcriptome profiling of huanglongbing (HLB) tolerant and susceptible citrus plants reveals the role of basal resistance in HLB tolerance. Front. Plant Sci. 7:933.

Xu, Q., Chen, L.-L., Ruan, X., Chen, D., Zhu, A., Chen, C., Bertrand, D., Jiao, W.-B., Hao, B.-H., and Lyon, M. P. 2013. The draft genome of sweet orange (Citrus sinensis). Nat. Genet. 45:59-66.

Zhu, K. Y., Merzendorfer, H., Zhang, W., Zhang, J., and Muthukrishnan, S 2016. Biosynthesis, turnover, and functions of chitin in insects. Annu. Rev. Entomol. 61:177-196. 